\title{
A Fault Data Capture Method for Water Quality Monitoring Equipment Based on Structural Pattern Recognition
}

\author{
Hao Yang ${ }^{1,2,3,4,6}$, Daoliang $\mathrm{Li}^{1,2,3,4,5, *}$, and Yong Liang ${ }^{6}$ \\ ${ }^{1}$ Key Laboratory of Agricultural Information Acquisition Technology, \\ Ministry of Agriculture, Beijing 100083, P.R. China \\ ${ }^{2}$ Beijing Engineering and Technology Research Center for Internet of Things in Agriculture, \\ Beijing 100083, P.R. China \\ ${ }^{3}$ China-EU Center for Information and Communication Technologies in Agriculture, \\ China Agricultural University, Beijing 100083, P.R. China \\ ${ }^{4}$ Beijing Engineering Center for Advanced Sensors in Agriculture, \\ Beijing 100083, P.R. China \\ ${ }^{5}$ College of Information and Electrical Engineering, China Agricultural University, \\ Beijing, 100083, P.R. China \\ ${ }^{6}$ Institute of Informatics Science and Engineering, Shandong Agricultural University, \\ Tai' an, 271018, P.R. China \\ dliangl@cau.edu.cn
}

\begin{abstract}
To capture equipment fault in real time and automate fault diagnosis, a pattern recognition method, based on data eigenvector and TCP transport protocol, was proposed to capture Water Quality Monitoring equipment's fault information. Fault data eigenvector was designed after analyzing the equipment fault feature and capture strategy, structural pattern recognition strategy was confirmed and specific data frame was designed in response to the fault data eigenvector, by integrating the data frame design into the equipment's communication protocol, data related to different fault compiled into fault data frames by transmitters or communication module of equipment's different components, the remote sever captures equipment fault on transport via fault data frames according to the structural pattern recognition strategy. With 7 months of practical application in Taihu aquaculture project and research center of agricultural information technology, combining with historical fault data and contrast with artificial recognition result, the simulate experiment shows this method has higher response rate and process rate with a nice accurate.
\end{abstract}

Keywords: fault data capture, data eigenvector, transport layer, fault filter.

\section{Introduction}

Water quality parameters includes DO (dissolved oxygen), EC (electrical conductivity), SAL(solidity), WT (water temperature), PH and TUR (turbidity), all of

\footnotetext{
* Corresponding author.

D. Li and Y. Chen (Eds.): CCTA 2013, Part II, IFIP AICT 420, pp. 423-433, 2014.

(C) IFIP International Federation for Information Processing 2014
} 
these parameters effect deeply to aquaculture management and breeding decision, so collecting water quality parameters is an extremely important work to aquaculture. The Water quality monitoring equipment in the paper is made to collect water quality parameters in time and offer water quality optimization services include SMS warning, oxygenation and other services. Equipment have been deployed in maricultural breeding bases and industrial aquaculture in Beijing, Tianjin, Hebei, Shandong, Jiangsu and Guangdong. Nevertheless, equipment fault prevents farmers from increasing more reliance on the equipment, researches must be done to develop fault diagnosis technology and form an integrated strategy.

ANNs requires large amount of sample data for training, as its process is pure mathematical procedure [1-13]. There are many fault detection methods applied the support vector machine [14].

Fault detection should be an independent step in fault diagnosis process, fault diagnosis should base on fault data captured by fault detection step, and serious redundancy calculations exist in diagnosis process.

\section{Data Eigenvector Analysis}

\subsection{Equipment Faults Description}

Equipment faults are divided into five types due to component types. Namely sensor faults, transmitter faults, actuator faults, GPRS gateway faults and remote server faults, see fig1.

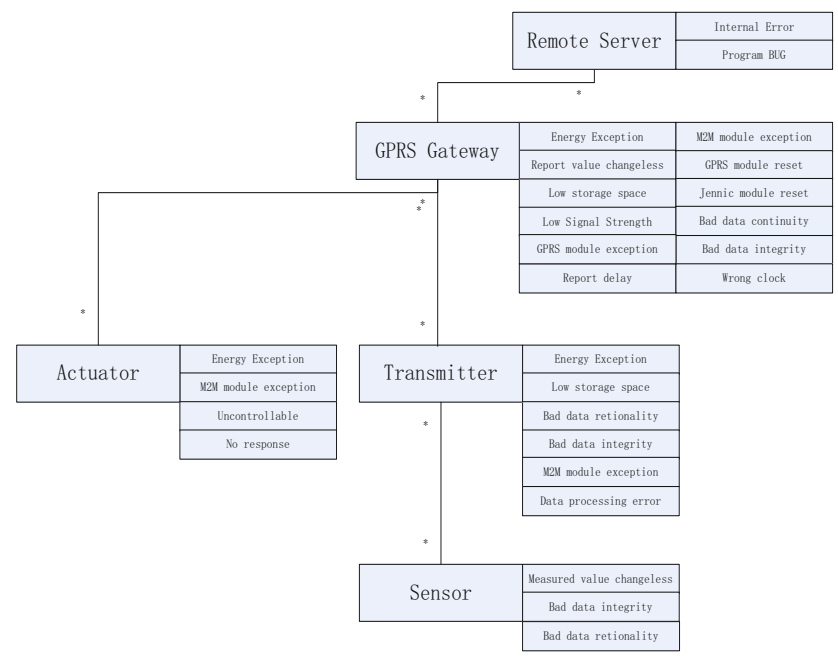

Fig. 1. Equipment fault tree

When combined with some high-class arithmetic like support vector machine to solve fault capture task in every node, long training time cost is not acceptable. 


\subsection{Data Eigenvector Related to different Equipment Faults}

To an object represents a specific fault, recognition arithmetic need to judge whether it contains fault information according data eigenvector, for each fault type, there is a specific eigenvector and type record; these records are listed in Form 1.

Form1. Data type and eigenvector corresponding to different faults

\begin{tabular}{|c|c|c|}
\hline Recognition target & Data type & Eigenvectors \\
\hline Uncontrollable & Actuator state & Response data and executive result \\
\hline No response & Actuator state & Response data \\
\hline Energy Exception & M2M state & $\begin{array}{l}\text { Power supply mode } \& \text { nominal voltage } \\
\qquad \& \text { measured value }\end{array}$ \\
\hline Low storage space & $\begin{array}{c}\text { Device } \\
\text { information }\end{array}$ & Residual capacity calculated value \\
\hline $\begin{array}{l}\text { Jennic module } \\
\text { exception }\end{array}$ & M2M state & Jennic module reset times \\
\hline $\begin{array}{l}\text { M2M module } \\
\text { exception }\end{array}$ & M2M state & $\begin{array}{l}\text { M2M signal value and emission } \\
\text { frequency }\end{array}$ \\
\hline Data process error & M2M state & Conversion formula \\
\hline Wrong clock & GPRS state & GPRS gateway clock \\
\hline $\begin{array}{l}\text { GPRS module } \\
\text { exception }\end{array}$ & GPRS state & $\begin{array}{c}\text { State code } \& \text { SIM card state } \& \text { heart beat } \\
\text { interval }\end{array}$ \\
\hline $\begin{array}{l}\text { GPRS module } \\
\text { exception }\end{array}$ & GPRS state & Reset times \\
\hline Low Signal strength & $\begin{array}{c}\text { GPRS } \\
\text { state/Device state }\end{array}$ & Signal emission frequency \\
\hline Internal error & $\begin{array}{l}\text { Message from } \\
\text { server }\end{array}$ & Error code \\
\hline Program BUG & None & Server crash \\
\hline Bad data integrity & Record & $\begin{array}{l}\text { Actual record count divide theoretical } \\
\text { record count } \& \text { sensor state }\end{array}$ \\
\hline Bad data continuity & Record & Actual record interval time \\
\hline Report delay & Record & Report time minus collected time \\
\hline $\begin{array}{l}\text { Report value } \\
\text { changeless }\end{array}$ & Record & value \& sensor collect voltage value \\
\hline Bad data rationality & Record & Value change rate \& value \\
\hline
\end{tabular}

\section{$3 \quad$ Method and Capture Strategy}

\subsection{Data Transfer Process on Transport Layer}

Data frame format was proposed in the following passage. Form. 2 is the transmitting data frame format. 
Form2. Transmitting Data Frame Format

\begin{tabular}{|c|c|c|c|c|c|c|c|c|c|}
\hline Length & $\begin{array}{l}2 \\
\text { byte } \\
\text { s }\end{array}$ & $\begin{array}{l}1 \\
\text { byte } \\
\text { s }\end{array}$ & $\begin{array}{l}1 \\
\text { bytes }\end{array}$ & $\begin{array}{l}1 \\
\text { bytes }\end{array}$ & $\begin{array}{l}2 \\
\text { bytes }\end{array}$ & $\begin{array}{l}\text { M } \\
\text { bytes }\end{array}$ & $\mathrm{N}$ bytes & $\begin{array}{l}2 \\
\text { bytes }\end{array}$ & 2 bytes \\
\hline Content & $\begin{array}{l}\text { Start } \\
\text { seg } \\
\text { men } \\
\mathrm{t}\end{array}$ & $\begin{array}{l}\text { Fra } \\
\text { me } \\
\text { type }\end{array}$ & $\begin{array}{l}\text { Fram } \\
\mathrm{e} \\
\text { lengt } \\
\mathrm{h}\end{array}$ & $\begin{array}{l}\text { Frame } \\
\text { code }\end{array}$ & $\begin{array}{l}\text { Contro } \\
1 \text { code }\end{array}$ & $\begin{array}{l}\text { Addr } \\
\text { ess } \\
\text { segm } \\
\text { ent }\end{array}$ & $\begin{array}{l}\text { Data } \\
\text { segment }\end{array}$ & $\begin{array}{l}\text { CRC } \\
\text { check }\end{array}$ & $\begin{array}{l}\text { Termin } \\
\text { al }\end{array}$ \\
\hline $\begin{array}{l}\text { Descrip } \\
\text { tion }\end{array}$ & & & & Head & & & $\begin{array}{c}\text { Eigenvect } \\
\text { or data } \\
\text { frame }\end{array}$ & & Гail \\
\hline
\end{tabular}

The eigenvector data frames and fault filter introduced in following passages are based on the data frame format and this protocol.

\subsection{Define Eigenvector Data Frames and Frame Filter}

The design of eigenvector data frame is shown in form 3 below. Eigenvector type is corresponding to the frame code; form 4 is the detail design of eigenvector data frame model.

Form3. Eigenvector data frame format

\begin{tabular}{|c|c|c|c|c|}
\hline & Type & $\begin{array}{c}\text { GPRS gateway } \\
\text { clock/Report time }\end{array}$ & $\begin{array}{c}\text { Eigenvector } \\
\text { type }\end{array}$ & $\begin{array}{c}\text { Eigenvector } \\
\text { data }\end{array}$ \\
\hline $\begin{array}{c}\text { Lengt } \\
\mathrm{h}\end{array}$ & 2 bytes & 6 bytes & 1 bytes & $\mathrm{N}$ \\
\hline
\end{tabular}

Form4. Detail Design of Eigenvector Data Frame Model

\begin{tabular}{|c|c|c|c|c|}
\hline \multicolumn{2}{|c|}{ Eigenvector source Frame code } & Type code & Eigenvetor type & Description \\
\hline \multirow{7}{*}{$\begin{array}{l}\text { GPRS gateway } \\
\text { state }\end{array}$} & \multirow{7}{*}{ 0x01 } & \multirow[t]{2}{*}{$\begin{array}{l}\text { Link } \\
\text { heartbeat:[0x01][0x00]; }\end{array}$} & $\begin{array}{l}\text { Device heart beat } \\
\text { interval time }\end{array}$ & Hexadecimal value \\
\hline & & & Reporting cycle & Hexadecimal value \\
\hline & & State heartbeat: & $\begin{array}{l}\text { Acquisition } \\
\text { cycle }\end{array}$ & Hexadecimal value \\
\hline & & $\begin{array}{l}\text { long connection: } \\
{[0 \mathrm{x} 02][0 \times 01]}\end{array}$ & Storage cycle & Hexadecimal value \\
\hline & & $\begin{array}{l}\text { Short } \\
\text { connection:[0x02][0x02] }\end{array}$ & Signal strength & Hexadecimal value \\
\hline & & \multirow{2}{*}{$\begin{array}{l}\text { no connection: } \\
{[0 \times 02][0 \times 03]}\end{array}$} & $\begin{array}{l}\text { Not reported data } \\
\text { count }\end{array}$ & Hexadecimal value \\
\hline & & & Gateway voltage & Hexadecimal value \\
\hline
\end{tabular}




\begin{tabular}{|c|c|c|c|c|}
\hline \multirow{6}{*}{ M2M state } & \multirow{6}{*}{$0 \times 02$} & $\begin{array}{l}\text { Power on: } \\
{[0 \mathrm{x} 01][0 \mathrm{x} 00]}\end{array}$ & \multirow{3}{*}{ Energy type } & 0x00:battery \\
\hline & & \multirow{5}{*}{$\begin{array}{l}\text { Pause: } \\
{[0 x 02][0 x 00]} \\
\text { Power } \\
\text { off:[0x03][0x00] }\end{array}$} & & 0x01:electric supply \\
\hline & & & & 0x02:solar pannel \\
\hline & & & $\begin{array}{l}\text { Device reset } \\
\text { time }\end{array}$ & Hexadecimal value \\
\hline & & & $\begin{array}{l}\text { Not reported } \\
\text { data count }\end{array}$ & Hexadecimal value \\
\hline & & & Deivce voltage & Hexadecimal value \\
\hline \multirow{6}{*}{ Record } & \multirow{6}{*}{$0 x 03$} & \multirow{6}{*}{$\begin{array}{l}\text { Channel } \\
\text { count:Generated by } \\
\text { sending device, } \\
\text { equals the amount of } \\
\text { channels belong to } \\
\text { the device }\end{array}$} & Channel number & Hexadecimal value \\
\hline & & & & DO:0x00; \\
\hline & & & Channel twne & EC:0x01; \\
\hline & & & ferlantiel yуре & WT:0x02; \\
\hline & & & & PH:0x03; \\
\hline & & & channel value & Hexadecimal value \\
\hline \multirow{13}{*}{ Actuator state } & \multirow{13}{*}{$0 x 04$} & $\begin{array}{l}\text { Power on: } \\
{[0 \mathrm{x} 01][0 \mathrm{x} 00]}\end{array}$ & \begin{tabular}{|l|} 
Channels \\
corresponding to \\
control action \\
\end{tabular} & olHexadecimal value \\
\hline & & $\begin{array}{l}\text { Pause: } \\
{[0 \mathrm{x} 02][0 \mathrm{x} 00]}\end{array}$ & \multirow{8}{*}{ Control trigger } & 0x00:unknown \\
\hline & & $\begin{array}{l}\text { Power off: } \\
{[0 \mathrm{x} 03][0 \mathrm{x} 00]}\end{array}$ & & 0x01:timing \\
\hline & & \multirow{16}{*}{$\begin{array}{l}\text { No action: } \\
{[0 \mathrm{x} 04][0 \mathrm{x} 00]}\end{array}$} & & 0x02:automatic \\
\hline & & & & 0x03:remote control \\
\hline & & & & 0x04:manual operation \\
\hline & & & & 0x05 exception protect \\
\hline & & & & 0x06:Illeagal control \\
\hline & & & & 0x07:SMS control \\
\hline & & & \multirow{4}{*}{ Control type } & 0x00:power on \\
\hline & & & & 0x01:pause \\
\hline & & & & 0x02:power off \\
\hline & & & & 0x03:no action \\
\hline \multirow{6}{*}{ Actuator state } & \multirow{6}{*}{$0 x 04$} & & \multirow{4}{*}{$\begin{array}{l}\text { State feedback } \\
\text { type }\end{array}$} & 0x00:poer on \\
\hline & & & & 0x01:pause \\
\hline & & & & 0x02:power off \\
\hline & & & & 0x03:running \\
\hline & & & $\begin{array}{l}\text { State feedback } \\
\text { channels }\end{array}$ & Hexadecimal value \\
\hline & & & $\begin{array}{l}\text { Original channel } \\
\text { value }\end{array}$ & Hexadecimal value \\
\hline
\end{tabular}


A frame filter is designed here to filter eigenvector information from data frames with a high rate. The filter design is showed in Form 5.

Form5. Data filter design

\begin{tabular}{llll}
\hline Process & Byte number & $\begin{array}{l}\text { Mask } \\
\text { code }\end{array}$ & Description \\
\hline 1 & 1 & 0xFF & $\begin{array}{l}\text { Extract the first byte, whose low three bits maybe } \\
\text { the high three bits of the frame length. }\end{array}$ \\
2 & 4 & 0xFF & $\begin{array}{l}\text { Extract the length of this frame } \\
3\end{array}$ \\
4 & 6 & 0xFF & Extract the frame code. \\
4 & 6 & 0xF0 & Address type \\
4 & 7 & 0x0F & Address type \\
4 & 7 & 0xF0 & Address type \\
5 & 8 & 0x0F & Address type \\
6 & $9 \sim 9+\mathrm{M}$ & 0xF0 & Address description \\
7 & $9+\mathrm{M} \sim 11+\mathrm{M}$ & 0xF...F & Device address \\
8 & $11+\mathrm{M} \sim 17+\mathrm{M}$ & 0xF...F & Report time/ GPRS Gateway clock \\
9 & $17+\mathrm{M} \sim 18+\mathrm{M}$ & 0xFF & Eigenvector type \\
10 & $18+\mathrm{M} \sim 18+\mathrm{M}+\mathrm{N}$ & 0xF...F & Eigenvector value \\
\hline
\end{tabular}

\subsection{A Method to Capture Fault by Filtering Data Frame}

Form 6 is the recognize rule.To explain the process more clearly and detail, the filtering process is shown in the following fig2. Fig3 introduces recognition strategy respectively for GPRS gateway fault, because of space limit, device fault, record fault and actuator fault recognition strategy is not introduced here. 
Form6. Recognize rule

\begin{tabular}{|c|c|c|}
\hline Data type & Recognize parameter & Recognize result \\
\hline GPRS & & \\
\hline $\begin{array}{l}\text { Gateway } \\
\text { state }\end{array}$ & No GPRS connection & GPRS offline \\
\hline $\begin{array}{l}\text { GPRS } \\
\text { Gateway } \\
\text { state }\end{array}$ & GPRS signal strength $<16$ & $\begin{array}{l}\text { Communication error: low } \\
\text { signal strength }\end{array}$ \\
\hline $\begin{array}{l}\text { GPRS } \\
\text { Gateway } \\
\text { state }\end{array}$ & $\begin{array}{l}\text { SIM card service stopped or Reset times in } 24 \\
\text { hours }>1 \text { or Heart beat interval time }>10 \text { minutes }\end{array}$ & GPRS module exception \\
\hline GPRS & Reporting cycle $>$ heart beat interval time & Bad data integrity \\
\hline Gateway & Device voltage $<5$ & Low device voltage \\
\hline state & GPRS clock time difference $>5$ minutes & Wrong GPRS clock \\
\hline $\begin{array}{l}\text { Device } \\
\text { state }\end{array}$ & Device power off & Device shut down \\
\hline $\begin{array}{l}\text { Device } \\
\text { state }\end{array}$ & $\begin{array}{l}\text { Device voltage as the high byte and energy type } \\
\text { as the low byte }\end{array}$ & $\begin{array}{l}<0 \mathrm{x} 0502 \text {, solar pannel } \\
\text { exception }\end{array}$ \\
\hline $\begin{array}{l}\text { Device } \\
\text { state }\end{array}$ & $\begin{array}{l}\text { Device voltage as the high byte and energy type } \\
\text { as the low byte }\end{array}$ & $\begin{array}{l}<0 x 0501 \text {,electric supply } \\
\text { exception }\end{array}$ \\
\hline $\begin{array}{l}\text { Device } \\
\text { state }\end{array}$ & $\begin{array}{l}\text { Device voltage as the high byte and energy type } \\
\text { as the low byte }\end{array}$ & $<0 x 0500$,battery exception \\
\hline $\begin{array}{l}\text { Device } \\
\text { state }\end{array}$ & Device reset time $>1$ in 24 hours & M2M module exception \\
\hline $\begin{array}{l}\text { Device } \\
\text { state }\end{array}$ & Signal strength $<50$ & $\begin{array}{l}\text { Communication error:Low } \\
\text { signal strength }\end{array}$ \\
\hline $\begin{array}{l}\text { Device } \\
\text { state }\end{array}$ & Report time difference $>5$ minutes & Report delay \\
\hline $\begin{array}{l}\text { Device } \\
\text { state }\end{array}$ & Not reported data count $>200$ in 24 hours & Bad data integrity \\
\hline Record & Report data value changeless & $\begin{array}{l}\text { M2M communication } \\
\text { exception }\end{array}$ \\
\hline Record & Report data value out the threshold & Bad data rationality \\
\hline Record & Unnormal report data value change rate & Bad data rationality \\
\hline Record & Report time difference $>5$ minutes & Report delay \\
\hline Record & $\begin{array}{l}\text { (Data count/heart beat count)/(Heart beat } \\
\text { interval time/data collection cycle) }\end{array}$ & $>1$, GPRS connection fault \\
\hline Record & $\begin{array}{l}\text { (Data count/heart beat count)/(Heart beat } \\
\text { interval time/data collection cycle) }\end{array}$ & $<1$,Bad data integrity \\
\hline $\begin{array}{l}\text { Actuator } \\
\text { state }\end{array}$ & $\begin{array}{l}\text { Actuator state code equals [0x02 } 0 \mathrm{x} 00] \text { or } \\
\text { [0x03 0x00] }\end{array}$ & Uncontrollable \\
\hline $\begin{array}{l}\text { Actuator } \\
\text { state }\end{array}$ & Actuator state code equals [0x04 0x00] & No response \\
\hline $\begin{array}{l}\text { Actuator } \\
\text { state }\end{array}$ & Report delay & $\begin{array}{l}\text { Report time } \\
\text { difference }>5 \text { minutes }\end{array}$ \\
\hline
\end{tabular}




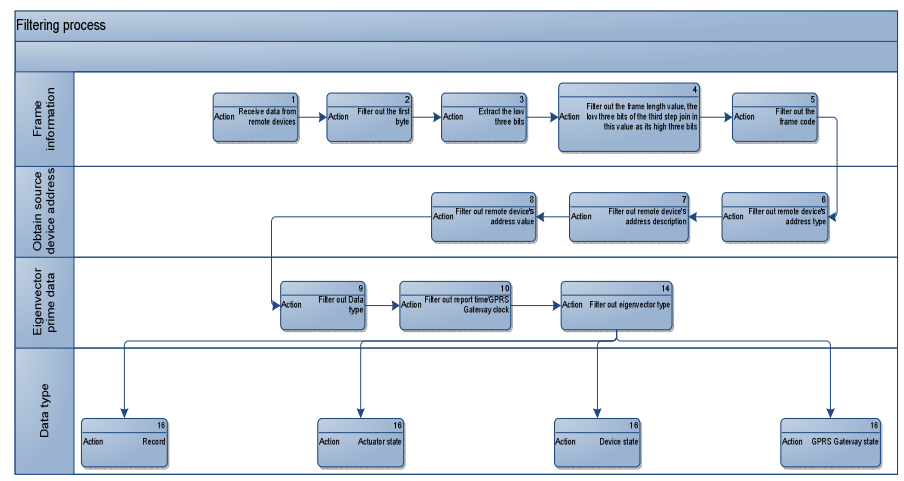

Fig. 2. Filtering process

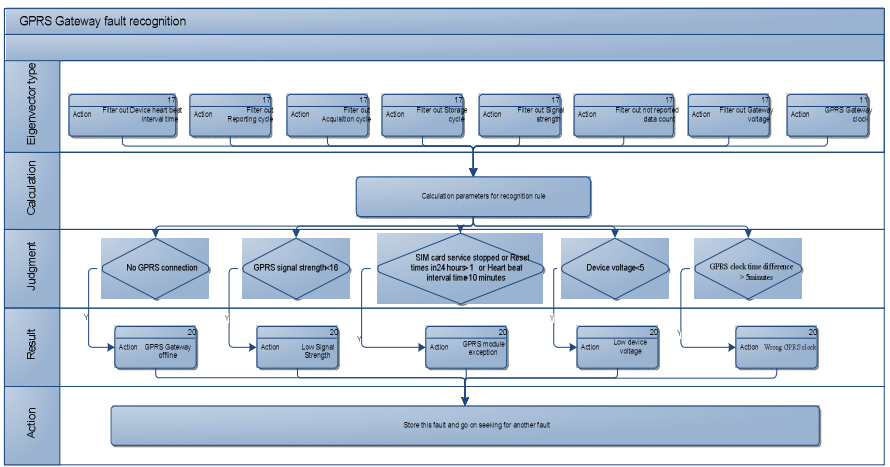

Fig. 3. GPRS Gateway Fault Recognition Strategy

\section{Simulation Experiment and Discussion}

\subsection{Simulation Strategy and Build Simulation LAN}

To verify the strategy's processing rate and accuracy, different personal computers with simulating IP addresses are regarded as the GPRS gateways to report collected data to remote server. The experiment LAN structure is shown in fig4.

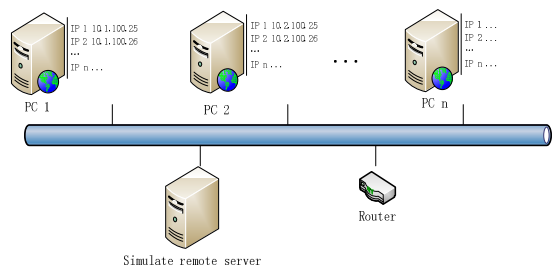

Fig. 4. Experiment LAN Structure 
The router simulate the GPRS service, simulate remote server is another PC, simulate remote server receive the data frame via TCP/IP protocol and telnet service, then decode and filter the data frames with programs based on the fault recognition strategy in chapter 3.3. The program are written in java and based on apache mina framework.

\subsection{Experiment Result and Evaluation}

1290 records of fault are found from working log of operation and maintenance team is used in the experiment. The program was divided into two executable jar file, namely Simulation Server and Simulation Gateway. Fig 5 to 6 shows simulation experiment process and result.

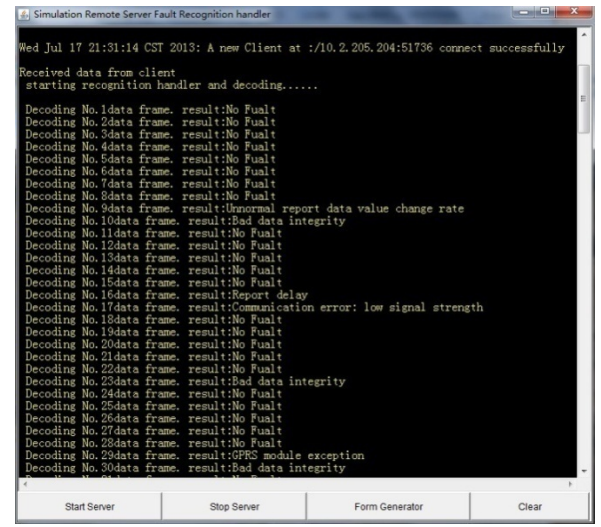

Fig. 5. Handling process

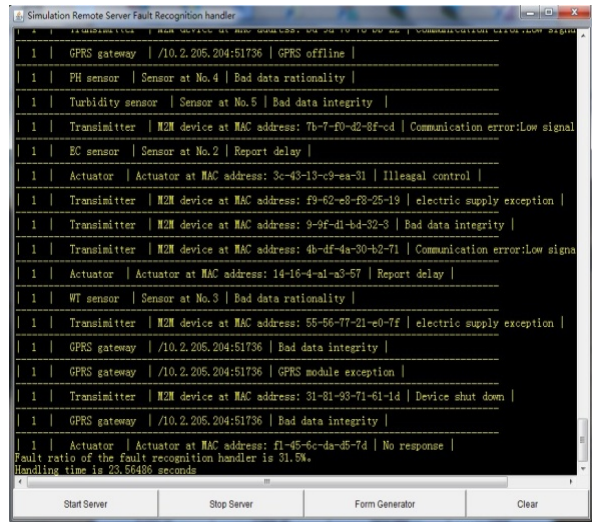

Fig. 6. Result and evaluation

The first experiment is to get the accuracy of the recognition method under different actual fault record ratio, and total records' count is fixed to 200. The experiment result is shown in fig7. The second experiment is about the accuracy under different total record count, the result is shown in fig8.

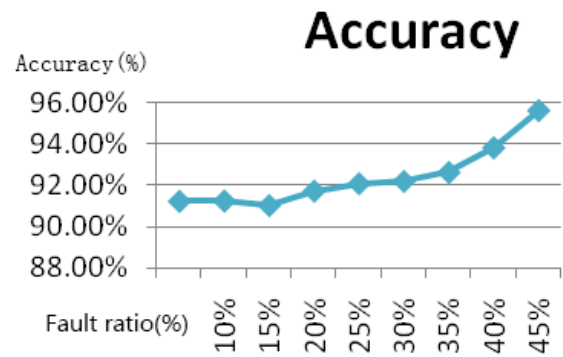

Fig. 7. Accuracy under Different Actual Fault Record Ratio

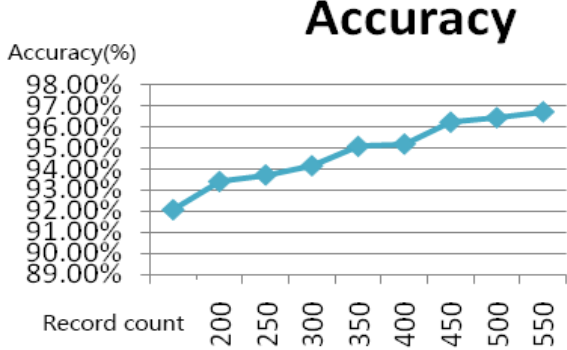

Fig. 8. Accuracy under Different Total Record Count 
The last experiment is to test the time-cost under different fault record count, as the strategy time-cost is mainly on recognized fault records' handling, so this experiment change the fault record count and take the average fault records' handling time as the time-cost evaluation parameter, total record count is fixed to 400. The average fault records' handling time equals total handling time divides 400 . The result proves the handling time is proportional to fault record count, as shown in fig .22.

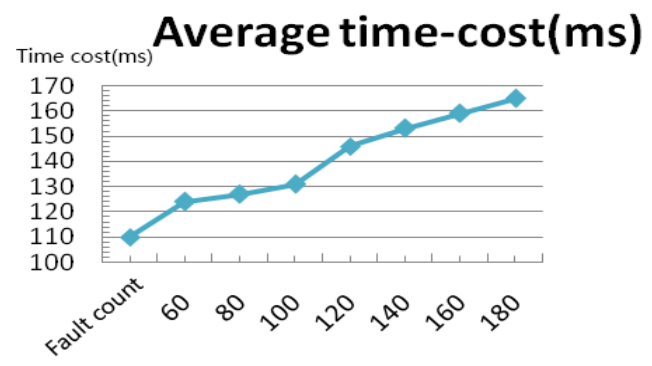

Fig. 9. Average time-cost

\subsection{Application Effect}

The recognition strategy was applied in the Water Quality Monitoring system developed by China Agricultural University, the program has been deployed on the remote server of the system since December, 2012, by now it recognized 246586 records, and is still running on the server. Its high efficient, low time-cost and nice accuracy received praises of maintenance team.

\section{Conclusions}

The proposed pattern recognition method, based on data eigenvector and TCP transport protocol analyses the Water Quality Monitoring equipment comprehensively. The author designed the data transport protocol based on transmit rule, based on this transport protocol, the data filter is proposed. According to actual diagnosis experiment and knowledge, added threshold to the data filter, as a result, the filter is able to filter out data that beyond the threshold. A novel recognition method is proposed to handle fault data with high efficiency and low time-cost, the method is a combination of four strategies, the strategy is specifically, the method manage these strategies to cooperation more efficient.

After 7 months' application, program based on the proposed method performed well on Water Quality Monitoring system. Work logs and praises from maintenance team prove the method feasible and efficient.

Nevertheless, because of the shortage of eigenvector analysis and filter design, recognition misses and errors exist, the method has potential to be improved better, further research should focus on the reduction of the recognition misses and errors. Moreover, relative diagnosis algorithm is necessary to be designed. 
Acknowledgement. Financial support from state science and technology support program (2011BAD21B01). Data, diagnosis knowledge and device support from device maintenance team of Research Center of Agricultural information technology. China Agricultural University is gratefully acknowledged.

\section{References}

[1] Wu, K., Choudhury, D., Matsumoto, H.: Wireless Power Transmission, Technology, and Applications. In: Proceedings of The IEEE, vol. 101(6SI), pp. 1271-1275 (2013)

[2] Xiaodan, P., et al.: Uplink transmission in the W-band $(75-110 \mathrm{GHz})$ for hybrid optical fiber-wireless access networks. Microwave and Optical Technology Letters 55(5), 1033-1036 (2013)

[3] Lakshmanan, S., Sivakumar, R.: Proteus: Multiflow Diversity Routing for Wireless Networks with Cooperative Transmissions. IEEE Transactions on Mobile Computing 12(6), 1146-1159 (2013)

[4] Cheng, S.T., et al.: Hierarchical Distributed Source Coding Scheme and Optimal Transmission Scheduling for Wireless Sensor Networks. Wireless Personal Communications 70(2), 847-868 (2013)

[5] Tahir, Y.H., et al.: Transmission of Visual Data over Wireless Fading Channel in Real-Time Systems Based on Superposition Coding Scheme. Arabian Journal for Science and Engineering 38(6), 1459-1469 (2013)

[6] Chunlai, Y., et al.: Study on Wireless Energy and Data Transmission for Long-Range Projectile. IEEE Transactions on Plasma Science 41(5), 1370-1375 (2013)

[7] Refaat, S.S., et al.: ANN-based for detection, diagnosis the bearing fault for three phase induction motors using current signal. In: 2013 IEEE International Conference on Industrial Technology (ICIT 2013), pp. 253-258 (2013)

[8] Talebi, H.A., Khorasani, K.: A Neural Network-Based Multiplicative Actuator Fault Detection and Isolation of Nonlinear Systems. IEEE Transactions on Control Systems Technology 21(3), 842-851 (2013)

[9] Jettanasen, C., Ngaopitakkul, A.: A novel probabilistic neural network-based algorithm for classifying internal fault in transformer windings. IEEJ Transactions on Electrical and Electronic Engineering 8(2), 123-131 (2013)

[10] Prieto, M.D., et al.: Bearing Fault Detection by a Novel Condition-Monitoring Scheme Based on Statistical-Time Features and Neural Networks. IEEE Transactions on Industrial Electronics 60(8), 3398-3407 (2013)

[11] Li, B., et al.: Applying the fuzzy lattice neurocomputing (FLN) classifier model to gear fault diagnosis. Neural Computing \& Applications 22(3-4SI), 627-636 (2013)

[12] Liu, H., et al.: Adaptive neuro-fuzzy inference system based faulty sensor monitoring of indoor air quality in a subway station. Korean Journal of Chemical Engineering 30(3), $528-539$ (2013)

[13] Hashemi, M., Safizadeh, M.S.: Design of a fuzzy model based on vibration signal analysis to auto-detect the gear faults. Industrial Lubrication and Tribology 65(3), 194-201 (2013)

[14] Keskes, H., Braham, A., Lachiri, Z.: Broken rotor bar diagnosis in induction machines through stationary wavelet packet transform and multiclass wavelet SVM. Electric Power Systems Research 97, 151-157 (2013) 